\title{
SODIUM CROMOGLYCATE MUCOADHESIVE BUCCAL PATCHES: DESIGN, FABRICATION, IN VITRO AND IN VIVO CHARACTERIZATION
}

\author{
SHEREEN AHMED SABRY \\ Department of Pharmaceutics and Industrial Pharmacy, Faculty of Pharmacy, Zagazig University, Zagazig, Egypt \\ Email: shereensabry134@yahoo.com
}

Received: 21 Sep 2017, Revised and Accepted: 09 Jan 2018

\section{ABSTRACT}

Objective: The purpose of this study was to design and formulate mucoadhesive buccal patches of sodium cromoglycate (SCG) as an alternative way to overcome its poor oral absorption and short half-life.

Methods: Mucoadhesive patches were prepared by solvent casting technique using cellulose acetate butyrate (CAB) alone or in combination with mucoadhesive polymers like SCMC (sodium carboxymethyl cellulose), HPMC 100M (hydroxyl propyl methyl cellulose) and Cbp934P (carbopol) in different concentrations. The successful patches were evaluated for thickness, weight variation, folding endurance, tensile strength, drug content, surface pH, moisture uptake, swelling percentage, mucoadhesion strength, residence time, in vitro release study, ex vivo permeation and in vivo pharmacokinetic studies.

Results: The thickness of all prepared patches ranged from $0.210 \pm 0.006$ to $0.355 \pm 0.012$, folding endurance was more than 300 , weight variation did not exceed $0.179 \pm 0.015$, tensile strength and $\%$ elongation ranged from $6.4 \pm 0.018$ to $13.1 \pm 0.024$, and from $30.4 \pm 0.88$ to $53.4 \pm 0.78$ respectively. The swelling percentage after one hour was from $20.8 \pm 0.99$ to $53.2 \pm 1.5$. $\mathrm{pH}$ of all prepared patches did not exceed 6.8 , the drug content was about 99 to $101 \%$, moisture uptake did not exceed $10 \%$. Mucoadhesion strength and residence time ranged from $17.2 \pm 0.14$ to $51.2 \pm 0.26$, and from $3.35 \pm 0.25$ to $7.45 \pm 0.28$ respectively. The cumulative release percentage of SCG was in the following descending order $C A B>C A B$ with $C b p 934 P>C A B$ with HPMC $>$ CAB with SCMC. The optimized patch (F9) decreased the $\mathrm{C}_{\max }$ and increased $\mathrm{T}_{\max }$ compared to the parenteral solution.

Conclusion: It can be concluded that mucoadhesive buccal patch is a promising dosage form to prolong the release of SCG and enhance its poor oral bioavailability.

Keywords: Buccal patches, Sodium cromoglycate, Solvent casting

(C) 2018 The Authors. Published by Innovare Academic Sciences Pvt Ltd. This is an open-access article under the CC BY license (http://creativecommons.org/licenses/by/4.0/) DOI: http://dx.doi.org/10.22159/ijap.2018v10i2.24333

\section{INTRODUCTION}

Although oral drug delivery remains the most common and preferred route for delivery of many drugs, it suffers from several important drawbacks such as enzymatic degradation along the gastrointestinal tract, first pass metabolism, delayed onset of absorption and sometimes poor absorption. These defects necessitate the importance of designing alternative dosage forms to be administered through alternative routes such as pulmonary, transdermal, ocular, rectal, vaginal and buccal. The buccal route overcomes the disadvantages associated with the oral route for systemic drug delivery [1, 2]. These include avoidance of first-pass metabolism and enzymatic degradation, rapid onset of absorption, prolonged release of certain drugs and ease administration of drugs [3]. Buccal patches suffer from certain limitations which include [4]: certain drugs which have undesirable taste, irritate buccal mucosa, unstable in buccal $\mathrm{pH}$, discolor the teeth and drugs with large dose could not be formulated as buccal patches. Mucoadhesive buccal patches are more recent dosage form which is designed to give systemic or local drug delivery and fabricated to overcome the short residence time of oral gel which is easily washed by saliva [5] and discomfort of solid dosage forms like tablets. Sodium cromoglycate is a mast cell stabilizer that inhibits the release of inflammatory mediators and prevents the immediate onset and delayed onset asthma $[6,7]$. It suffers from poor oral absorption, which is found to be $0.5 \%$ of the total administered dose and short plasma half-life which is 60-90 min [8]. This research work aims to design, formulate and evaluate mucoadhesive buccal patches of SCG to overcome its poor oral absorption and prolonged its release and consequently enhances its bioavailability.

\section{MATERIALS AND METHODS}

\section{Materials}

Sodium cromoglycate was kindly supplied by sigma company, Egypt. Phosphoric acid and Potassium-dihydrogen phosphate were purchased from El Nasr Company Egypt. HPLC grade acetonitrile, SCMC, Cbp934 P and HPMC100M were purchased from Sigma-Aldrich Chemie, Germany. All other chemicals and solvents are of analytical grade. Diethyl ether was purchased from Fine Chem. Ltd. (India).

\section{Methods}

Preparation of mucoadhesive buccal patches

The solvent casting technique was used for the preparation of SCG mucoadhesive patch [9-12]. The composition of the successful patches was illustrated in table 1 . The calculated amount of the drug and polyethyleneglycol 600 as a plasticizer $(50 \% \mathrm{~W} / \mathrm{W}$ of dry polymer weight) were dissolved in a $20 \mathrm{ml}$ mixture of absolute ethanol and methylene chloride (1:1) as casting solvent. The calculated amount of the polymer or polymer mixture was sprinkled onto the solution with occasional shaking. The casting solution was then adjusted to $25 \mathrm{ml}$ to give $4 \% \mathrm{~W} / \mathrm{V}$ polymeric solution and left for $24 \mathrm{~h}$ for complete dissolution and removal of suspended air bubbles. The solution was then cast in a glass petri dish (area=50.24 $\mathrm{cm}^{2}$ ) covered with inverted glass funnel to control the rate of evaporation and prevent patch blistering. The solvent was allowed to evaporate for $24 \mathrm{~h}$ at ambient room temperature. The dry patch was isolated and cut into square sections of $2 \times 2 \mathrm{~cm}$, each containing $20 \mathrm{mg}$ of SCG and finally wrapped in an aluminium foil and stored in a desiccator.

Evaluation of mucoadhesive buccal patches

\section{Physical appearance}

All prepared buccal patches were visually inspected for clarity, smoothness and flexibility.

\section{Thickness}

The thickness of three patches of each formulation was measured with a digital micrometre (Cole-Parmer Instrumental Co., Japan) at five different places and the mean thickness was determined [13]. 
Table 1: Composition of successful sodium cromoglycate buccal mucoadhesive patches

\begin{tabular}{|c|c|c|c|c|c|}
\hline Formula code & SCG (mg) & CAB (mg) & Cbp934p (mg) & CMCS (mg) & HPMC100M (mg) \\
\hline F1 & 20 & 1000 & & & \\
\hline F2 & 20 & 800 & 200 & ---- & ---- \\
\hline F3 & 20 & 700 & 300 & ---- & ---- \\
\hline $\mathrm{F} 4$ & 20 & 600 & 400 & ---- & --- \\
\hline F5 & 20 & 500 & 500 & --- & ---- \\
\hline F6 & 20 & 800 & --- & 200 & --- \\
\hline F7 & 20 & 700 & --- & 300 & --- \\
\hline F8 & 20 & 600 & --- & 400 & --- \\
\hline F9 & 20 & 500 & --- & 500 & --- \\
\hline F10 & 20 & 800 & --- & --- & 200 \\
\hline F11 & 20 & 700 & --- & --- & 300 \\
\hline F12 & 20 & 600 & --- & --- & 400 \\
\hline F13 & 20 & 500 & ---- & --- & 500 \\
\hline
\end{tabular}

SCG: sodium cromoglycate, CAB: cellulose acetate butyrate, Cbp934p: carbopol934p, SCMC: sodium carboxymethyl cellulose, HPMC100M: hydroxyl propyl methyl cellulose

\section{Weight variation}

All prepared patches were subjected to weight variation test by individually weighing three randomly selected patches $(2 \times 2 \mathrm{~cm})$ for each formula [14] using an electronic digital balance (Metter-Toledo, Ag, CH 8606, Greifensee, Switzerland).

\section{Tensile strength and percent elongation}

Tensile strength and percent elongation were determined using JJ load cell instrument 100n, j. j Lloyd instruments limited (warash, Southampton, England). The dried piece of each patch with uniform size $8 \times 100 \mathrm{~mm}$ was clamped using an upper and lower flat faced metal grip. The distance between the grips and the effective length of the patch under stress was kept constant at $40 \mathrm{~mm}$. A crosshead speed of $3 \mathrm{~mm} / \mathrm{min}$ was started. When the film broke, the force and elongation were measured $[15,16]$. The average of three measurements for each formula was determined. Tensile strength can be calculated according to the following equation:

$$
\text { Tensile strength }=\frac{\text { breaking load }}{\text { cross sectional area }(\mathrm{mm} 2)}
$$

Percent elongation can be determined according to the following equation:

$$
\text { Percent elongation }=\frac{\text { increasing in length }}{\text { original length }} \times 100
$$

\section{Surface pH}

SCG patch of each formula $(2 \times 2 \mathrm{~cm})$ was soaked for $1 \mathrm{~h}$ in $5 \mathrm{ml}$ distilled water at ambient room temperature. $\mathrm{pH}$ was determined by mounting the electrode of $\mathrm{pH}$ meter300 (Jenway LTD, UK) on the patch surface and permitting equilibration for $1 \mathrm{~min}$. The experiment was conducted in triplicate [17].

\section{Drug content uniformity}

SCG patch $2 \times 2 \mathrm{~cm}$ of each formula was dissolved in $100 \mathrm{ml}$ phosphate buffer $\mathrm{pH} 6.8$ with occasional stirring and then filtered. SCG was determined spectrophotometrically at $326 \mathrm{~nm}$ using UV-Spectrophotometer Shimadzu UV-1201, Japan against phosphate buffer pH 6.8 as a blank. The experiment was performed in triplicate [18].

\section{Folding endurance}

Folding endurance of each formula was conducted by folding section of $2 \times 2 \mathrm{~cm}$ size repeatedly at the same place till it broke or folded up to 300 times.

The value of folding endurance is expressed as the number of times the film could be folded at the same position without breaking. Folding endurance is given as the average of three determinations $[19,20]$.

\section{Moisture uptake}

The patches of all prepared formulations were placed in a desiccator containing $200 \mathrm{ml}$ saturated solution of potassium chloride to give relative humidity of $84 \%$ for $3 \mathrm{~d}$. At the end of the experiment, the patches were removed and weighed [21]. The percent moisture uptake of each patch was calculated according to the following equation:

$$
\text { Percent moisture uptake }=\frac{\text { final weight-initial weight }}{\text { initial weight }} \times 100
$$

\section{Percent swelling}

Square section of each patch measuring $2 \times 2 \mathrm{~cm}$ was carefully weighed, then immersed in $50 \mathrm{ml}$ phosphate buffer $\mathrm{pH} 6.8$ in a glass petri dish. The patch section was removed carefully at 5, 10, 15, 20, 30 and 60 min interval, dried carefully with the aid of filter paper and accurately weighed [22, 23]. Swelling percentage was calculated according to the following equation.

$$
\text { Swelling percentage }=\frac{\mathrm{Wt}-\mathrm{W} 0}{\mathrm{~W} 0} \times 100
$$

Where

$\mathrm{W} 0=$ the initial weight at zero time

$\mathrm{Wt}=$ the weight of the swollen patch at time $\mathrm{t}$.

Swelling percentage expressed as the average of three determinations.

\section{Ex-vivo mucoadhesion strength}

A modified physical balance was used for the determination of mucoadhesion strength of the prepared patches using the porcine buccal mucosa. The buccal mucosa was cut carefully into pieces and washed with pH 6.8 phosphate buffer. A piece of the porcine buccal mucosa was firmly tied to the open mouth of a glass vial which was completely filled with $\mathrm{pH} 6.8$ phosphate buffer. The glass vial was firmly fitted to the centre of a glass beaker which was filled with $\mathrm{pH}$ 6.8 phosphate buffer kept at $37 \pm 0.5^{\circ} \mathrm{C}$ to the level that just touches the mucosal surface. The patch was tightly stuck to the lower surface of the rubber stopper using cyanoacrylate adhesive. $5 \mathrm{~g}$ weight was put on right side pan for balancing the two pans. The weight was then removed, which lowered the pan along with the film over the mucosa. The balance was kept for $5 \mathrm{~min}$ at such position. Water then added slowly at a rate of $100 \mathrm{drops} / \mathrm{min}$ with the aid of the infusion set. The weight of water in grams that completely detached the patch from the surface of buccal mucosa was used in the calculation of mucoadhesion strength [24-26] according to the following equation:

Detachment stress $\left(\right.$ dyne $\left./ \mathrm{cm}^{2}\right)=\frac{\mathrm{m} . \mathrm{gr}}{\mathrm{A}}[27]$

Where $m$ is the weight of water in $g$ gr equal $980 \mathrm{~cm} / \mathrm{sec}^{2}$ the acceleration due to gravity

$A$ is the area of porcine mucosa equal to $\pi r^{2}$ where $r$ is the radius of the exposed porcine buccal mucosa.

\section{Ex-vivo mucoadhesion residence time}

Ex-vivo determination of mucoadhesion time was conducted using porcine buccal mucosa. The segment of the porcine mucosa was glued onto the internal side of a glass beaker using cyanoacrylate adhesive. The patch which was previously hydrated with $\mathrm{pH} 6.8$ phosphate buffer was then attached to the mucosa by applying light force for $20 \mathrm{Sec}$ with a fingertip. The beaker was then filled with $200 \mathrm{ml} \mathrm{pH} 6.8$ phosphate buffer and was kept at $37 \pm 0.5^{\circ} \mathrm{C}$ and 50 RPM in a thermostatic shaker 
water bath (Julabo SW-20 C, Germany). Ex-vivo mucoadhesion time is the time taken by the patch to erode or dislodge from the mucosa. The experiment was performed in triplicate [28].

\section{In vitro release study}

The cumulative drug release percent of SCG from different patches was conducted using USP type II dissolution apparatus paddle type. $2 \times 2 \mathrm{~cm}$ section of each formula was attached to a glass slide using cyanoacrylate adhesive. The glass slide was placed in the bottom of dissolution vessel. $500 \mathrm{ml} \mathrm{pH} 6.8$ phosphate buffer was used as the release medium and maintained at $37 \pm 0.5{ }^{\circ} \mathrm{C}$ and 50 RPM. $5 \mathrm{ml}$ sample was withdrawn at $1,2,3,4,5,6,7,8 \mathrm{~h}$ and replaced with an equal volume of fresh buffer. The samples were filtered, accurately diluted and analyzed spectrophotometrically at $326 \mathrm{~nm}$. The experiment was conducted in triplicate [29].

\section{Ex-vivo drug permeation study.}

Franz diffusion cell was used for the permeation study. The porcine oral mucosa was used as the model mucosal membrane. The buccal mucosa was washed and stabilized in phosphate buffer $\mathrm{pH} 6.8$ to remove any soluble component. The porcine mucosa was mounted between the donor and receptor compartments. $20 \mathrm{ml}$ phosphate buffer $\mathrm{pH} 6.8$ was filled into the receptor compartment maintained at $37 \pm 0.5^{\circ} \mathrm{C}$ and stirred using magnetic bead at 50 RPM. $3 \mathrm{ml}$ sample was withdrawn at a predetermined time interval and replaced with fresh buffer. The amount of SCG was estimated spectrophotometrically at $326 \mathrm{~nm}$. The experiment was performed in triplicate [30,31].

\section{In vivo pharmacokinetic study}

SCG was estimated in rabbit plasma by simple and sensitive RPHPLC method described by paparajusowjanya et al. [32] with certain modifications.

\section{Experimental design}

White male albino rabbits $(2-2.5 \mathrm{~kg})$ were used for the pharmacokinetic study. Animals were housed at the standardized condition of the animal house of faculty of pharmacy, Zagazig University, Zagazig, Egypt. All animals were acclimatized and kept constant at ambient room temperature. All animal procedures were performed in accordance with the approved protocol for the use of experimental animals set by the standing committee on the animal care of the faculty of pharmacy, Zagazig University, EgyptP3-122016. Animals were divided into three groups, each group of six rabbits. Group 1 act as a control, group 2 received the optimized patch F9 and group 3 received SCG solution parenterally. Group 2 and group 3 received a dose of $5 \mathrm{mg} / \mathrm{kg}$, which was determined by trials. Blood samples were withdrawn from the sinus orbital at 0.5 , $1,2,4,6,8,10,12,24 \mathrm{~h}$. The blood samples were centrifuged at 3000 RPM for 10 min. SCG was extracted from rabbit plasma by adding $100 \mu \mathrm{l}$ of $10 \%$ perchloric acid to precipitate the protein. $1 \mathrm{ml}$ rabbit plasma was vortexed for $1 \mathrm{~min}$, then $2 \mathrm{ml}$ diethyl ether was added. The mixture was centrifuged at $5000 \mathrm{RPM}$ and $4^{\circ} \mathrm{C}$ for $10 \mathrm{~min}$, then $2 \mathrm{ml}$ of the supernatant was taken and dried in a vacuum oven at 40 ${ }^{\circ} \mathrm{C}$. The residue was reconstituted with $20 \mu \mathrm{l}$ mobile phase and injected into the column.

\section{HPLC conditions}

HPLC (Waters Instrument, Germany) with the reverse phase C18 column. The UV detector was set at $240 \mathrm{~nm}$ for sample detection. The mobile phase consisted of acetonitrile and potassium di hydrogen ortho phosphate adjusted to $\mathrm{pH} 1.5$ with orthophosphoric acid in the ratio of 25:75 at a flow rate of $1 \mathrm{ml} / \mathrm{min}$. $10 \mathrm{mg}$ of SCG was dissolved in $10 \mathrm{ml}$ of mobile phase and suitably diluted to produce a stock solution of 1 $\mathrm{mg} / \mathrm{ml}$. Dilution of stock solution was performed to give $10,15,20,25$, $30,35 \mu \mathrm{g} / \mathrm{ml} .100 \mu \mathrm{l}$ of spiked plasma was added to each of the above concentrations and the samples were analyzed as previously described.

\section{Kinetic data analysis}

The cumulative drug release percentages were plotted according to the different kinetic models such as Higuchi diffusion, zero order, first order, Korsmeyer-Peppas, and Hixson and Crowell to determine the best kinetic model of the drug release [33].

\section{Statistical analysis}

The resulting data of different evaluated parameters were expressed as the average mean \pm standard deviation of the mean. One way analysis of variance (ANOVA) was employed for the data analysis using SPSS program, version 16 . The data were significant at a level $\mathrm{P}<0.05$.

\section{RESULTS AND DISCUSSION}

\section{Physical appearance and thickness}

All prepared patches were translucent and smooth. The average thickness of all patches was found in the range from $0.21 \pm 0.006$ to $0.355 \pm 0.012 \mathrm{~mm}$ (table 2).

\section{Weight variation}

The weight of all prepared patches $(2 \times 2 \mathrm{~cm})$ ranged from $0.155 \pm 0.025$ to $0.179 \pm 0.015 \mathrm{mg}$. The results in table 2 demonstrate the uniformity of weight of all prepared patches.

\section{Folding endurance}

The folding endurance of all prepared patches was more than 300 irrespective to the type of the polymer which ensures flexibility and toughness of all prepared patches (table 2) [34].

\section{Tensile strength and percent elongation}

Tensile strength and percent elongation give an indication for the elasticity and strength of the prepared patches. Soft and tough patches have the high tensile strength and percent elongation. Data recorded in table 2 show that the tensile strength of CAB patch (F1) was $6.4 \pm 0.018$ and percent elongation was $30.4 \pm 0.88$. The addition of mucoadhesive polymers increased both mechanical parameters. The effect of the mucoadhesive polymers can be ranked in the following order: SCMC $>$ HPMC $100 \mathrm{M}>\mathrm{CbP} 934 \mathrm{P}$. The amount of the mucoadhesive polymers had a non-significant effect. This was in a good correlation with patel et al. and Qadir et al. $[13,28]$. They found that the tensile strength of the buccal patches increased with increasing the percentage of HPMC $15 \mathrm{cp}$.

Table 2: Physico mechanical characterization of SCG patches.

\begin{tabular}{|c|c|c|c|c|c|}
\hline Formula code & $\begin{array}{l}\text { Thickness (mm) } \\
\pm \text { SD }\end{array}$ & Folding endurance & Tensile strength $(\mathrm{N} / \mathrm{MM} 2) \pm \mathrm{SD}$ & $\begin{array}{l}\text { \% elongation } \\
\pm \text { SD }\end{array}$ & Weight variation \pm SD \\
\hline F1 & $0.210 \pm 0.006$ & $>300$ & $6.4 \pm 0.018$ & $30.4 \pm 0.88$ & $0.155 \pm 0.025$ \\
\hline $\mathrm{F} 2$ & $0.230 \pm 0.012$ & $>300$ & $7.5 \pm 0.053$ & $39.5 \pm 0.71$ & $0.155 \pm 0.015$ \\
\hline F3 & $0.235 \pm 0.015$ & $>300$ & $8.6 \pm 0.185$ & $39.9 \pm 0.88$ & $0.158 \pm 0.025$ \\
\hline F4 & $0.240 \pm 0.006$ & $>300$ & $10.5 \pm 0.172$ & $43.5 \pm 0.55$ & $0.160 \pm 0.009$ \\
\hline F5 & $0.250 \pm 0.006$ & $>300$ & $10.6 \pm 0.125$ & $45.2 \pm 0.92$ & $0.157 \pm 0.013$ \\
\hline F6 & $0.240 \pm 0.002$ & $>300$ & $11.6 \pm 0.006$ & $47.9 \pm 0.75$ & $0.160 \pm 0.015$ \\
\hline F7 & $0.250 \pm 0.015$ & $>300$ & $11.8 \pm 0.120$ & $50.7 \pm 0.66$ & $0.158 \pm 0.009$ \\
\hline F8 & $0.305 \pm 0.023$ & $>300$ & $12.6 \pm 0.080$ & $51.5 \pm 0.68$ & $0.175 \pm 0.009$ \\
\hline F9 & $0.320 \pm 0.012$ & $>300$ & $13.1 \pm 0.024$ & $53.4 \pm 0.78$ & $0.169 \pm 0.019$ \\
\hline F10 & $0.235 \pm 0.015$ & $>300$ & $9.8 \pm 0.085$ & $43.2 \pm 0.88$ & $0.155 \pm 0.011$ \\
\hline F11 & $0.250 \pm 0.006$ & $>300$ & $10.4 \pm 0.006$ & $47.6 \pm 0.68$ & $0.157 \pm 0.019$ \\
\hline F12 & $0.312 \pm 0.025$ & $>300$ & $11.2 \pm 0.085$ & $49.1 \pm 0.92$ & $0.170 \pm 0.015$ \\
\hline F13 & $0.355 \pm 0.012$ & $>300$ & $12.1 \pm 0.120$ & $51.2 \pm 0.73$ & $0.179 \pm 0.015$ \\
\hline
\end{tabular}

*Data are expressed as mean \pm standard deviation of the mean (SD), $n=3$ 


\section{Percent swelling}

Swelling of the polymer is an important property for the prolonged release of the drug and good mucoadhesion. Table 3 demonstrates the percent swelling of different patches. It is observed that there was an increase in the percent swelling with time. The obtained results revealed that the addition of mucoadhesive polymers increased the percent swelling of all prepared patches compared to CAB (F1) alone which had the lowest percent swelling. It is clear that SCMC had the highest percent swelling (F6-F9) followed by HPMC100M (F10-F13) and finally Cbp934P (F2-F5) that had a poor influence on the percent swelling. This could be ascribed to the presence of more hydroxyl group in SCMC compared to both HPMC100M and Cbp934P [35].

Table 3: Swelling percentages of SCG patches

\begin{tabular}{|c|c|c|c|c|c|c|}
\hline Formula code & 5 (min) & 10 (min) & 15 (min) & 20 (min) & 30 (min) & 60 (min) \\
\hline F1 & $3.7 \pm 0.006$ & $5.2 \pm 0.01$ & $8.6 \pm 0.08$ & $10.2 \pm 0.09$ & $15.6 \pm 0.82$ & $20.8 \pm 0.99$ \\
\hline $\mathrm{F} 2$ & $4.8 \pm 0.006$ & $6.2 \pm 0.01$ & $10.7 \pm 0.05$ & $13.5 \pm 0.06$ & $18.6 \pm 0.54$ & $24.9 \pm 1.5$ \\
\hline F3 & $4.8 \pm 0.009$ & $7.8 \pm 0.008$ & $11.8 \pm 0.01$ & $14.6 \pm 0.08$ & $19.7 \pm 0.35$ & $25.9 \pm 0.85$ \\
\hline $\mathrm{F} 4$ & $5.6 \pm 0.08$ & $9.2 \pm 0.006$ & $12.6 \pm 0.009$ & $15.8 \pm 0.01$ & $19.6 \pm 0.85$ & $24.6 \pm 1.9$ \\
\hline F5 & $4.5 \pm 0.06$ & $8.9 \pm 0.01$ & $13.2 \pm 0.08$ & $16.7 \pm 0.009$ & $20.1 \pm 0.96$ & $26.2 \pm 0.58$ \\
\hline F6 & $3.5 \pm 0.006$ & $9.4 \pm 0.008$ & $16.8 \pm 0.08$ & $23.1 \pm 0.06$ & $25.5 \pm 0.54$ & $35.5 \pm 0.85$ \\
\hline F7 & $2.8 \pm 0.008$ & $8.6 \pm 0.006$ & $17.2 \pm 0.009$ & $27.1 \pm 0.09$ & $32.5 \pm 0.96$ & $40.4 \pm 1.5$ \\
\hline F8 & $3.5 \pm 0.006$ & $10.6 \pm 0.08$ & $19.2 \pm 0.006$ & $28.6 \pm 0.09$ & $35.2 \pm 0.87$ & $45.4 \pm 1.9$ \\
\hline F9 & $2.8 \pm 0.01$ & $8.2 \pm 0.08$ & $18.6 \pm 0.009$ & $26.8 \pm 0.04$ & $35.4 \pm 0.58$ & $53.2 \pm 1.5$ \\
\hline F10 & $2.6 \pm 0.008$ & $5.8 \pm 0.006$ & $10.2 \pm 0.08$ & $14.2 \pm 0.08$ & $18.2 \pm 0.99$ & $31.5 \pm 0.85$ \\
\hline F11 & $3.1 \pm 0.006$ & $7.2 \pm 0.008$ & $13.8 \pm 0.06$ & $15.6 \pm 0.09$ & $19.8 \pm 0.96$ & $35.4 \pm 0.96$ \\
\hline F12 & $3.5 \pm 0.01$ & $7.8 \pm 0.06$ & $14.5 \pm 0.06$ & $16.8 \pm 0.04$ & $20.5 \pm 1.5$ & $39.4 \pm 0.54$ \\
\hline F13 & $2.8 \pm 0.01$ & $9.4 \pm 0.08$ & $15.7 \pm 0.009$ & $18.2 \pm 0.04$ & $21.2 \pm 1.5$ & $41.5 \pm 0.85$ \\
\hline
\end{tabular}

*Data are expressed as mean \pm standard deviation of the mean (SD), $n=3$

\section{Surface pH}

The surface $\mathrm{pH}$ of all prepared patches was found to be in the range from 6.4 to 6.9, which indicates that the prepared patches are nonirritant to the buccal mucosa and expected to be palatable (table 4).

\section{Drug content}

Drug content of SCG buccal patches $(2 \times 2 \mathrm{~cm})$ was observed to be in the range from $97.8 \pm 0.08$ to $101.8 \pm 0.018$ (table 4) which ensures homogeneous and uniform distribution of the drug throughout the prepared patches.

\section{Moisture uptake}

The moisture uptake of all prepared patches ranged from $3.2 \pm 0.08$ to $10.8 \pm 0.25$ (table 4 ) which indicates that all prepared patches will remain stable and non-brittle with a poor chance of microbial attack [36]. It was found that the addition of mucoadhesive polymers increased the film hydrophilicity and resulted in a significant increase in moisture uptake [37]. Both HPMC 100M and SCMC increased moisture uptake more than Cbp934P compared to $\mathrm{CAB}$ alone (F1). The amount of mucoadhesive polymer had a nonsignificant effect on moisture uptake of the prepared patches.

\section{Ex-vivo mucoadhesion strength}

Table 4 illustrated the results of mucoadhesion strength of all prepared patches. It is clear that patch which was prepared from $\mathrm{CAB}$ alone (F1) had the lowest mucoadhesion strength (17.2 \pm 0.014$)$. The addition of mucoadhesive polymers increased the mucoadhesion significantly and their effect arranged in the following order SCMC $>$ HPMC100M $>$ CbP934P. It was observed that SCMC had the highest effect and Cbp934P had the lowest effect. Also, the results showed that the mucoadhesion behaviour is greatly influenced by the type of mucoadhesive polymer and increased with an increase in the concentration of hydrophilic polymer. The effect of SCMC could be attributed to the higher hydration and higher swelling. Shilpa et al. [38] found that buccal strips of pravastatin which were prepared from SCMC showed high mucoadhesion. Also, it was observed that HPMC had a lower effect on mucoadhesion compared to SCMC and this could be ascribed to the lack of proton donating carboxyl group which results in a decreased ability to form hydrogen bonds [39].

\section{Ex-vivo mucoadhesion residence time}

Ex-vivo mucoadhesion residence time of all prepared patches is presented in table 4. It is obvious from the results that incorporation of both HPMC $100 \mathrm{M}$ and SCMC increased the residence time while Cbp934P had no effect compared to CAB alone (F1). It was found that as the amount of SCMC increased from $200 \mathrm{mg}$ (F6) to $500 \mathrm{mg}$ (F9), there was an increase in the residence time from $6.75 \pm 0.28$ to $8.3 \pm 0.25$. The same behaviour was observed in case of HPMC $100 \mathrm{M}$ (F10-F13). The residence time of the prepared patches arranged as follows: SCMC $>$ HPMC100M $>$ CbP934P $>$ CAB. From the obtained results of both percent swelling and mucoadhesion strength, it can be predicted that there was a good correlation between them, this means that patch with higher percent swelling had higher mucoadhesion and remain attached to the buccal mucosa for a longer time.

Table 4: Physico mechanical characterization of SCG patches

\begin{tabular}{|c|c|c|c|c|c|}
\hline $\begin{array}{l}\text { Formula } \\
\text { code }\end{array}$ & $\begin{array}{l}\text { Surface } \\
\text { pH } \pm S D^{*}\end{array}$ & $\begin{array}{l}\text { Drug content } \\
(\%) \pm S D\end{array}$ & $\begin{array}{l}\text { Moisture uptake } \\
(\%) \pm \text { SD }\end{array}$ & $\begin{array}{l}\text { Mucoadhesion strength } \\
\left(* \text { dyne } / \mathrm{cm}^{2}\right) \pm S D\end{array}$ & $\begin{array}{l}\text { Residence } \\
\text { time(h) } \pm S D\end{array}$ \\
\hline F1 & $6.5 \pm 0.021$ & $100.8 \pm 1.2$ & $3.2 \pm 0.08$ & $17.2 \pm 0.14$ & $3.35 \pm 0.25$ \\
\hline $\mathrm{F} 2$ & $6.7 \pm 0.019$ & $98.6 \pm 0.08$ & $5.2 \pm 0.16$ & $19.1 \pm 0.26$ & $3.55 \pm 0.28$ \\
\hline F3 & $6.4 \pm 0.021$ & $99.7 \pm 0.08$ & $4.2 \pm 0.18$ & $21.6 \pm 0.21$ & $3.75 \pm 0.25$ \\
\hline $\mathrm{F} 4$ & $6.4 \pm 0.021$ & $101.0 \pm 1.5$ & $3.8 \pm 0.15$ & $24.2 \pm 0.26$ & $3.75 \pm 0.18$ \\
\hline F5 & $6.7 \pm 0.016$ & $97.8 \pm 0.08$ & $4.8 \pm 0.15$ & $25.6 \pm 0.18$ & $3.5 \pm 0.22$ \\
\hline F6 & $6.5 \pm 0.019$ & $98.8 \pm 0.06$ & $6.2 \pm 0.16$ & $31.6 \pm 0.25$ & $6.75 \pm 0.28$ \\
\hline F7 & $6.4 \pm 0.015$ & $99.5 \pm 1.6$ & $8.1 \pm 0.18$ & $37.6 \pm 0.18$ & $7.15 \pm 0.18$ \\
\hline F8 & $6.5 \pm 0.012$ & $99.2 \pm 0.08$ & $9.8 \pm 0.19$ & $41.1 \pm 0.15$ & $7.45 \pm 0.28$ \\
\hline F9 & $6.8 \pm 0.015$ & $98.2 \pm 0.18$ & $10.8 \pm 0.25$ & $51.2 \pm 0.26$ & $8.3 \pm 0.25$ \\
\hline F10 & $6.8 \pm 0.015$ & $99.4 \pm 1.8$ & $6.3 \pm 0.25$ & $23.2 \pm 0.18$ & $4.5 \pm 0.21$ \\
\hline F11 & $6.8 \pm 0.012$ & $101.2 \pm 1.7$ & $7.2 \pm 0.21$ & $25.1 \pm 0.11$ & $4.7 \pm 0.18$ \\
\hline F12 & $6.8 \pm 0.019$ & $99.8 \pm 1.9$ & $9.1 \pm 0.28$ & $28.5 \pm 0.22$ & $5.7 \pm 0.15$ \\
\hline F13 & $6.6 \pm 0.011$ & $101.8 \pm 0.018$ & $10.4 \pm 0.21$ & $30.2 \pm 0.17$ & $6.7 \pm 0.25$ \\
\hline
\end{tabular}

*Data are expressed as mean \pm standard deviation of the mean (SD), $n=3$ 


\section{In vitro release study}

In vitro release studies were performed in phosphate buffer $\mathrm{pH} 6.8$ to simulate buccal cavity. The release profiles of the prepared patches are clearly illustrated in figs. (1-3). It is obvious from the figs. that $95.2 \pm 1.4$ $\%$ of the incorporated dose released from F1 after $8 \mathrm{~h}$. The addition of Cbp934P had non-significant effect at low concentration as observed in F2 $(92.4 \pm 1.5)$ and F3 $(90.1 \pm 0.8)$ but upon increasing its concentration there was a slight but significant reduction in the amount of drug released after $8 \mathrm{~h}$, as observed in F4 $(89.1 \pm 1.3)$ and F5 (87.2 \pm 1.5 ) (fig. 1). It is clear from fig. 2 that incorporation of SCMC significantly retarded the release of SCG from F7 (87.1 \pm 0.8$)$, F8 $(82.1 \pm 1.5)$ and F9 $(75.2 \pm 1.1)$ after $8 \mathrm{~h}$. Similar behaviour was observed with HPMC100M (fig. 3). From the previous, it can be concluded that the mucoadhesive polymers retarded the release in the following order SCMC $>$ HPMC100M $>$ CbP934P. The retarding effect of SCMC and HPMC100M could be attributed to the fact that upon contact of both polymers with the dissolution medium, they undergo swelling forming a thick gel layer on the surface of the swollen patch which lead to an increase in the diffusional path length $[40,41]$ in addition to the prevention of the matrix disintegration by retarding penetration of the dissolution medium into the patch [42]. Magdy et al. found that montelukast released slowly from patches which were prepared from either SCMC or HPMC [14], Also, Mishra et al. found that incorporation of HPMC retarded the release of simvastatin from Eudragit RS-100 patches [43].

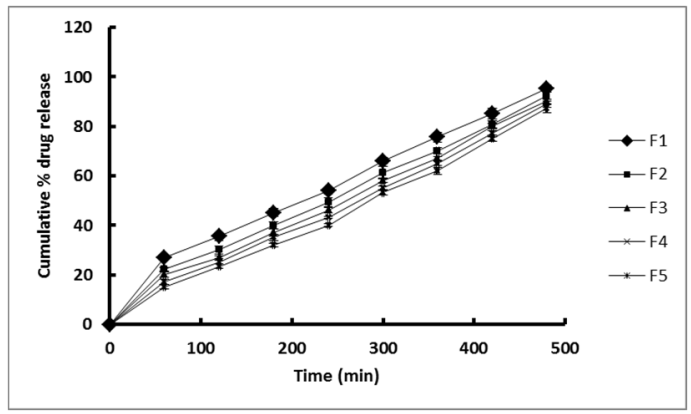

Fig. 1: Cumulative drug release percent of SCG from $\mathrm{CAB} \pm \mathrm{CbP934P}$ different patches, $n=3 \pm S D M$ (standard deviation of the mean)

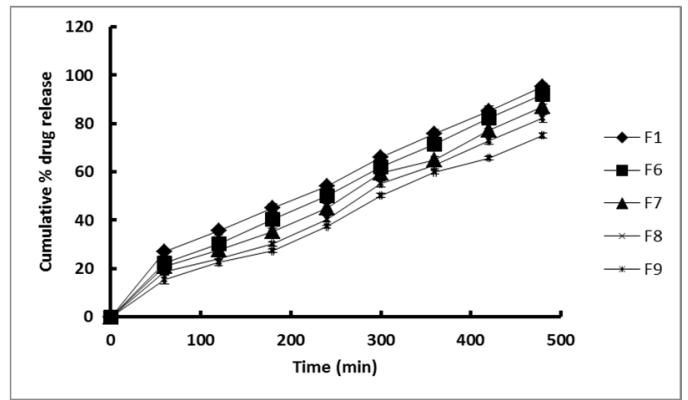

Fig. 2: Cumulative drug release percent of SCG from $\mathrm{CAB} \pm \mathrm{SCMC}$ different patches, $n=3 \pm S D$

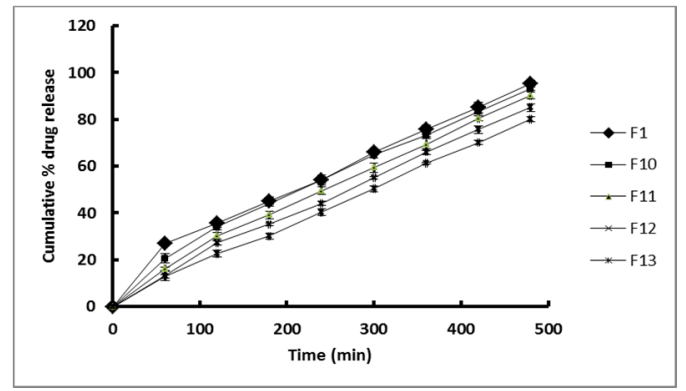

Fig. 3: Cumulative drug release percent of SCG from CAB \pm HPMC different patches, $n=3 \pm S D$

\section{Kinetic data analysis}

The in vitro release profile of all prepared mucoadhesive patches follow Higuchi diffusion model.

\section{Ex-vivo drug permeation study}

F5, F9 and F13 were selected for ex-vivo permeation through the porcine buccal mucosa based on their physicomechanical characters, release profiles and the used mucoadhesive polymer. It was found that $82.1 \pm 1.7,70.1 \pm 0.8$ and $75.6 \pm 1.5$ of the incorporated dose were permeated through the porcine buccal mucosa from F5, F9 and F13 respectively (fig.4). By comparing the release profile and permeation profile of each formula, it can be concluded that there was a good correlation between the release and permeation of SCG which gives a good evidence for the effective therapeutic response of the prepared patches. Mehraj udin et al. found that there was a good correlation between in vitro release data and ex-vivo permeation data of methyldopa from HPMC K47-PVP K30 patches [18].

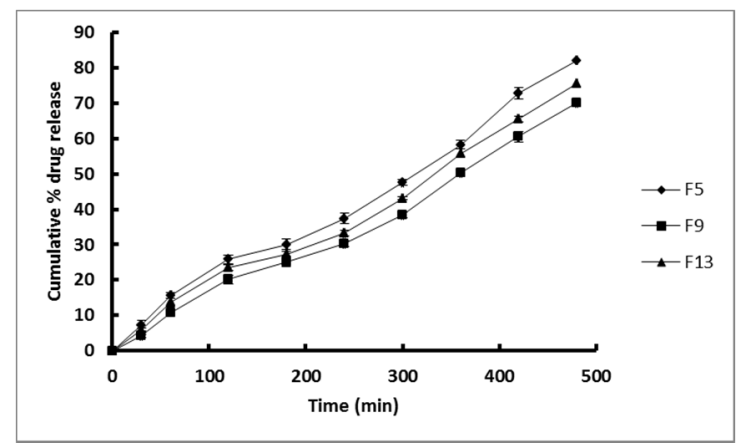

Fig. 4: Cumulative drug release percent of SCG permeated through the porcine buccal mucosa, $n=3 \pm S D M$

\section{In vivo pharmacokinetic study}

Fig.5 shows the chromatogram of the rabbit plasma of SCG. It can be observed that well-resolved peak obtained at 5.4 min for SCG. Fig. 6 represents the plasma profile of SCG optimized patch (F9) and parenteral solution as a function of time. It is clearly observed that there was a significant difference in the mean plasma concentration of both parenteral solution and mucoadhesive patch at all-time intervals. Table 5 depicts the mean pharmacokinetic parameters of tested formulae. From the illustrated results, it can be noticed that after administration of parenteral solution of SCG the peak plasma concentration was $14.2 \pm 1.2 \mu \mathrm{g} / \mathrm{h} / \mathrm{ml}$ and reached rapidly after $1.15 \pm 0.06 \mathrm{~h}$, whereas peak plasma concentration of mucoadhesive patch was $9.9 \pm 0.08 \mu \mathrm{g} / \mathrm{h} / \mathrm{ml}$ and reached after $3.85 \pm 0.008 \mathrm{~h}$. The increase in $\mathrm{T}_{\max }$ and the decrease in $\mathrm{C}_{\max }$ of SCG patch compared to parenteral solution suggests a sustained release effect with a good bioavailability.

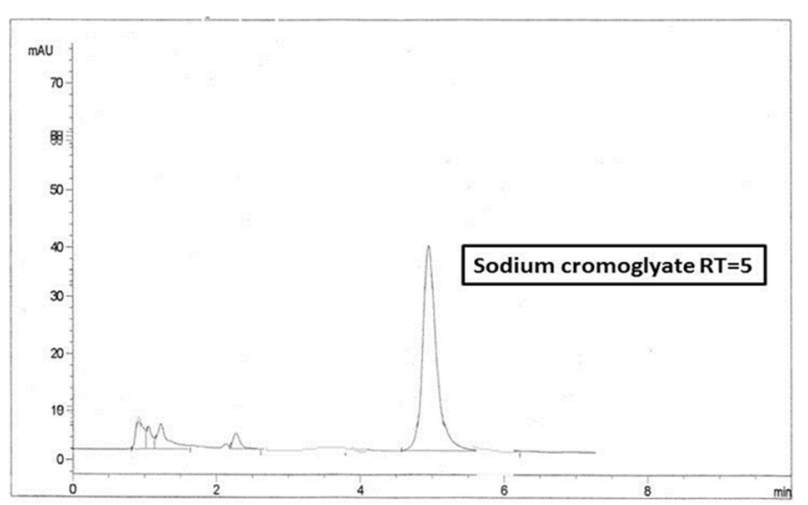

Fig. 5: Typical HPLC chromatogram of SCG in rabbit plasma 
Table 5: Pharmacokinetic parameters of SCG patch and parenteral solution

\begin{tabular}{|c|c|c|c|}
\hline Formula & Cmax $(\mu \mathrm{g} / \mathrm{h} / \mathrm{ml}) \pm \mathrm{SD}^{*}$ & Tmax (h) \pm SD & $\mathrm{AUC}_{0-24} \pm \mathrm{SD}$ \\
\hline SCG patch (F9) & $9.9 \pm 0.08$ & $3.85 \pm 0.008$ & $10.76 \pm 0.85$ \\
\hline Parenteral solution & $14.2 \pm 1.2$ & $1.15 \pm 0.06$ & $10.12 \pm 0.56$ \\
\hline
\end{tabular}

*All results are expressed as the mean of six determinations \pm standard deviations of the mean (SD)

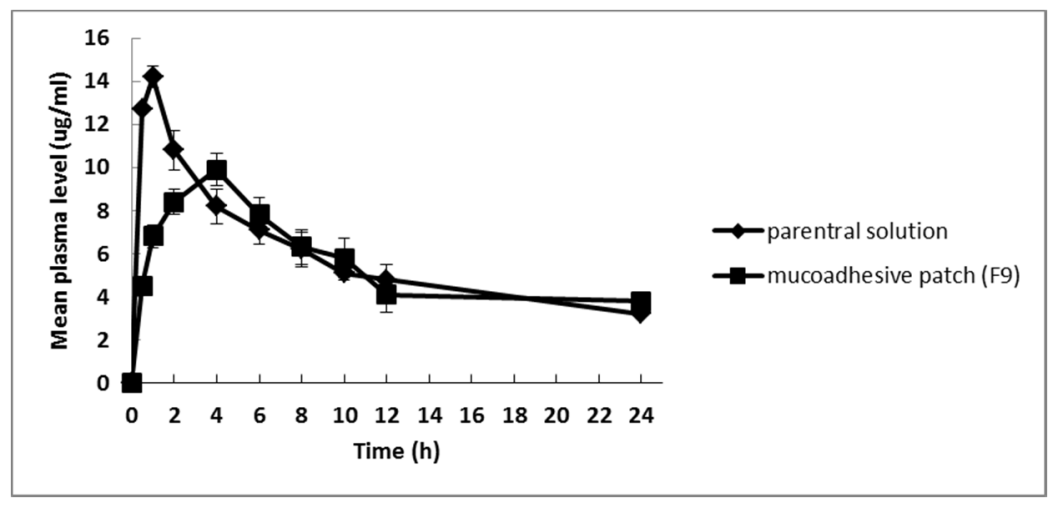

Fig. 6: Mean plasma levels of SCG of the parenteral solution and optimized mucoadhesive buccal patch F9, Sample size $=6 \pm$ SD

\section{CONCLUSION}

From the previous results it can be concluded that mucoadhesive buccal patches which were prepared from cellulose acetate butyrate and carboxy methyl cellulose sodium (F9) showed a good in vitro characteristics, an enhanced bioavailability and considered a promising dosage form to solve the poor oral absorption and short half-life of the drug.

\section{AUTHOR CONTRIBUTION}

All the work have been carried out by me

\section{CONFLICT OF INTERESTS}

No conflict of interest

\section{REFERENCES}

1. Puratchikody A, Prasanth VV, Mathew ST, Ashok KB. Buccal drug delivery: past, present and future-a review. Int J Drug Delivery 2011;3:171-84.

2. Kianfar F, Antonijevic MD, Chowdry BZ, Boateng JS. Formulation development of a carrageenan-based delivery system for buccal drug delivery using ibuprofen as a model drug. J Biomater Nanobiotechnol 2011;2:582-95.

3. Satyabrata B, Ellaiah P, Choudhury R, Murthy KVR, Bibhutibhusan P, Kumar MS. Design and evaluation of methotrexate buccal mucoadhesive patches Int J Pharm Biomed Sci 2010;1:31-6.

4. Patil BS, Tate SS, Kulkarni U, Hariprasanna RC, Wadageri GV. Development and in vitro evaluation of mucoadhesive buccal tablets of tizanidine hudrochloride using natural polymer xanthan gum. Int J Pharm Sci Rev Res 2011;8:140-6.

5. Andres R, Merkle HP. Evaluation of laminated mucoadhesive patches for buccal drug delivery. Int J Pharm 1989;49:231-40.

6. Gould MK, Raffin TA. Pharmacological management of acute and chronic bronchial asthma. Adv Pharmacol 1995;32:169-74.

7. Murphy S. Cromolyn sodium: basic mechanusms and clinical usage. Pediatr Asthma Allergy Immunol 1988;2:237-54.

8. WWW.Druginfosys.com. [Last accessed on 10 Nov 2017].

9. Khanna R, Agrawal SP, Alka Ahuja. Preparation and evaluation of mucoadhesive buccal films of clotrimazole for oral candida infections. Ind J Pharm Sci 1997;59:299-306.

10. Borsadia S, $\mathrm{O}^{\prime}$ Halloran D, Osborne JL. Quick dissolving films-a novel approach to drug delivery. Drug Delivery Technol 2003;3:63-6.
11. Mahajan A, Chhabra N, Aggrawal G. Formulation and characterization of fast dissolving buccal films. A review. Pharm Lett 2011;3:152-65.

12. Kumar VRS. Formulation and evaluation of mucoadhesive buccal patch of atorvastation. Int J Pharm Sci 2013;4:3391-407.

13. Khanusiya AQ, Charyulu RN, Prabhu P, Bhatt S, Shastry SC. Formulation and evaluation of fast dissolving films of loratadine for sublingual use. Int Res J Pharm 2012;3:158-61.

14. Mohamed MI, Afifi EAMR, Mekhael MKG. Formulation and evaluation of anti-asthmatic drug montelukast in mucoadhesive buccal patches. J Coast Life Med 2014;2:907-14.

15. Garsuch V, Kreutz JB. Novel analytical methods for the characterization of oral wafers. Eur J Pharm Biopharm 2009;73:195-201.

16. Sagban TH, Ismail KY. Formulation and evaluation of orodispersible film of sildenafil citrate. Int J Pharm Pharm Sci 2014;6:81-6.

17. Khairnar A, Jain P, Baviskar D, Jain D. Development of mucoadhesive buccal patches containing aceclofenac: in vitro evaluation. Int J PharmTech Res 2009;1:978-81.

18. Ganaie M, Mohan G, Sharma S, Mohi Ud Din S, Shukla TP, Hassan I. Formulation development and evaluation of mucoadhesive buccal film of methyldopa. J Global Trends Pharm Sci 2014;5:1893-904.

19. Tarun P, Kumar SV, Kumar TA. Formulation and evaluation of buccal patch of selective $\alpha 1$ receptor blocker prazosin HCL. Indo Am J Pharm Res 2013;3:4293-303.

20. Semalty M, Semalty A, Kumar G. Formulation and characterization of mucoadhesive buccal films of glipizide. Ind J Pharm Sci 2008;70:43-8.

21. Mangilal T, Soundarya K, Nagaganesh M, Ravikumar M. Formulation and evaluation of voriconazole patches for buccal drug delivery system. Eur J Biomed Pharm Sci 2017;4:529-35.

22. Rao NGR, Suryakar VB. Formulation and evaluation of montelukast sodium mucoadhesive buccal patches for chronic asthma attacks. Int J Pharma Bio Sci 2010;1:1-14.

23. Bhimavarapu R, Nissankararao Dr S, Vaidya VS, Sandhyasree S, shamili MS, devi BR. Development and in vitro evaluation of mucoadhesive buccal patches of sertraline HCL. Am J Adv Drug Delivery 2013;1:313-22.

24. Bhatt N, Patel K, Patel M, Patel N. Formulation and effect of polymers on a mucoadhesive buccal patch of carvedilol using factorial design. Am J PharmTech Res 2012;2:1134-53.

25. Edith M, Donald EC, Claus ML. Bioadhesive drug delivery system. Marcel Dekker Inc; 1999. p. 541-62. 
26. Patel JS, Rao KP. Design and evaluation of mucoadhesive buccal patches of diclofenac sodium. Ind J Pharm Sci 2003;4:420-2.

27. Khan S, patil K, Bobade N, Yeole P, Gaikwad R. Formulation of intranasal mucoadhesive temperature mediated in situ gel containing ropinirole and evaluation of brain targeting efficiency in rats. J Drug Target 2010;18:223-34.

28. Patel N, Prabhu P, Dubey A, Kamath JV. Design and evaluation of buccal patch containing combination of hydrochlorothiazide and lisinopril. RGUHS J Pharm Sci 2015;5:142-54.

29. Ratnakar NKC, Lalani R, Parikh RK. Design of a novel buccoadhesive system for unidirectional release of valsartan. J Pharm Sci Biosci Res 2014;4:85-91.

30. Baviskar D, Khaiirnar A, Jain P, Jain D. Development of the mucoadhesive buccal patch containing aceclofenac: in vitro evaluations. Int J PharmTech Res 2009;1:978-81.

31. Chimmiri P, Rajalakshmi R, Ramesh G, Rajesh K, Mahitha B, Bharat GK. Design and characterization of buccal film of tramadol hydrochloride. Int J Biol Pharm Res 2012;3:347-53.

32. Sowjanya P, Srinath N, Sumanth KS, Chaitanya D, Sai AP, Padmaja V. Validated RP-HPLC method for estimation of sodium cromoglycate in human plasma. Int J Pharm Res Dev 2013;5:112-20.

33. Kumar KK, Swathi M, Srinivas L, Basha SN. Formulation and evaluation of floating in situ gelling systems of losartan potassium. Pharm Lett 2015;7:98-12.

34. Aswathy SN, Vidhya KM, Saranya TR, Sreelakshmy KR, Sreeja $\mathrm{CN}$. A mucoadhesive buccal patch of cefixime trihydrate using biodegradable natural polymer. Int J Pharm Pharm Sci 2014;6:366-71.

35. Bahuguna K, Kothiyal GP. Formulation and evaluation of buccal patches of rosuvastatin. Ind J Novel Drug Del 2015;7:177-83.

36. Balaji Dr A, Krishnaveni B, Goud V. Formulation and evaluation of mucoadhesive buccal films of atorvastatin using natural protein. Int J Pharm Pharm Sci 2014;6:332-7.

37. Wu T, Pan W, Chen J, Zhang R. Studies of drug permeability and mechanical properties of free films prepared by cellulose acetate pseudolatex coating system. Drug Dev Ind Pharm 2000;26:95-102.

38. Shilpa L, Vasavi P, Devireddy SR. Buccal delivery of pravastatin. Formulation development and evaluation. Int J Pharm Tech 2015;6:7195-10.

39. Pramod KTM, Shivakumar HG. Novel core in cup buccoadhesive systems and films of terbutaline sulphate development and in vitro evaluation. Asian J Pharm Sci 2006;1:175-87.

40. Mohamed MI, Haider M, Ali M. Buccal mucoadhesive patches containing anti-hypertensive drug: in vitro and in vivo evaluation. J Chempharm 2011;3:665-86.

41. Yehia SA, EL-Gazayerly ON, Basalious EB. Fluconazole mucoadhesive buccal films: in vitro and in vivo performance. Curr Drug Delivery 2009;6:17-27.

42. Sekhar KC, Naidu KV, Vishnu YV, Gannu R, Kishan V, Rao YM. Transbuccal delivery of chlorpheniramine maleate from muccoadhesive buccal patches. Drug Delivery 2008;15:185-91.

43. Mishra S, Kumar G, Kothiyal PO. Formulation and evaluation of buccal patches of simvastatin by using different polymers. Pharma Innovation 2012;1:87-92. 